\title{
Success Factors of Extracorporeal Shock Wave Lithotripsy (ESWL) for Renal \& Ureteric Calculi in Adult
}

\author{
Ammar Fadil Abid \\ Medical College, Al-Mustansirya University, Al-Yarmouk Teaching Hospital, Baghdad, Iraq \\ Email: amarfadil@yahoo.com
}

Received 24 December 2013; revised 24 January 2014; accepted 31 January 2014

Copyright (c) 2014 by author and Scientific Research Publishing Inc.

This work is licensed under the Creative Commons Attribution International License (CC BY). http://creativecommons.org/licenses/by/4.0/

\section{(c) (i) Open Access}

\section{Abstract}

The purpose of this study was to define factors that have a significant impact on the stone-free rate after ESWL. Methods: A total of $\mathbf{4 1 7}$ patients harboring renal or ureteral stones underwent extracorporeal shock wave lithotripsy (ESWL) between October 2008 and July 2012. Eighty five patients were lost on follow up. The remaining $(n=332)$. All patients were $>18 \mathrm{yr}$ of age. Siemens and SLX-F2 electromagnetic machines were used to impart shock waves. Patients were stratified according to localization (pelvic, calyceal, or ureteral stones) and stone size (up to $10 \mathrm{~mm}, 10$ - 20 $\mathrm{mm}$, and $>20 \mathrm{~mm}$ ). Result: The overall success rate was 251/332 (75.6\%) achieve stone free status. Repeated ESWL sessions were needed in 258 (61.9\%). Of eleven variables were studied including age, sex, side, location (pelvic, calyx, ureter), ureteric stent, previous renal surgery, stone size, number of shock waves, opacity of stone, renal system state, and type of lithotripter, three variables were significantly affect the success rate namely stone size, number of shock waves and location of stone. Conclusions: ESWL remains one of the most commonly utilized treatments for patients with upper urinary tract calculi; Stone diameter, location, and number of shock waves, are the most important predictors determining stone clearance after ESWL of renal and ureteric calculi. To optimize treatment outcomes with ESWL the presence of treating urologist is essential to optimize the final result.

\section{Keywords}

ESWL; Renal Stone; Ureteric Stone; Success Factors

\section{Introduction}

Extracorporeal shock wave lithotripsy (ESWL) is considered the first line treatment for the majority of patients 
with renal and ureteric calculi. There is a considerable variability in reported treatment results of SWL with success rates from contemporary series varying from $60 \%$ to $90 \%$ [1]-[4].

Many factors are thought to influence the final results of ESWL, including patient selection, stone size, stone location and lithotripter type, in addition to experience level of the operator, total shock number, energy delivered, shock frequency and method of shock delivery [5] [6].

Success rates with modern lithotripters are less than those reported historically. Therefore, a fundamental question remains unresolved: how can we maximize the likelihood of treatment success when performing ESWL $[5]$ ?

We conducted analysis to determine the most significant factors that influence on the success of ESWL of renal and ureteric calculi.

\section{Patients and Methods}

From October 2008-July 2012, a total of 417 patients age harboring renal or ureteral stones, all patients $>18$ yr. underwent extracorporeal shock wave lithotripsy (ESWL). Eighty-five patients were excluded lost on follow up. Remaining $(n=332)$.

This study included 233 males (70.1\%) and 99 females (29.9\%). Patients with a mean (SD, range) age of 42.8 yr $( \pm 12.85)$.

\subsection{Stones}

Stones $(n=332)$ were stratified according to localization (pelvic, calyceal, or ureteral stones) and stone size (upto $10 \mathrm{~mm}, 10-20 \mathrm{~mm},>20 \mathrm{~mm}$ ). The localization of ureter and calyceal stones was not further specified. Stone size was determined by measuring the longest diameter on KUB for opaque stone, while lucent stone diameter measured by ultrasound scanning or CT scan.

Pre-procedural evaluation included urinalysis and serum creatinine. Plain abdominal film was taken routinely to evaluate radio-opacity and stone size [7].

\subsection{Technique of ESWL}

All treatments were done using electromagnetic lithotripter, Siemens $(n=200)$ and Storz SLX-F2 $(n=132)$. Treatment session consist of 3000 shock waves, all procedures were performed under analgesia. Briefly, tramadol $1-2 \mathrm{mg} / \mathrm{kg}$ and diclofenac $75 \mathrm{mg}$ IM.

Post ESWL patient were asked to pass urine into container, we found that stone either pass into small pieces or sand like particularly in lucent stone Figure 1.
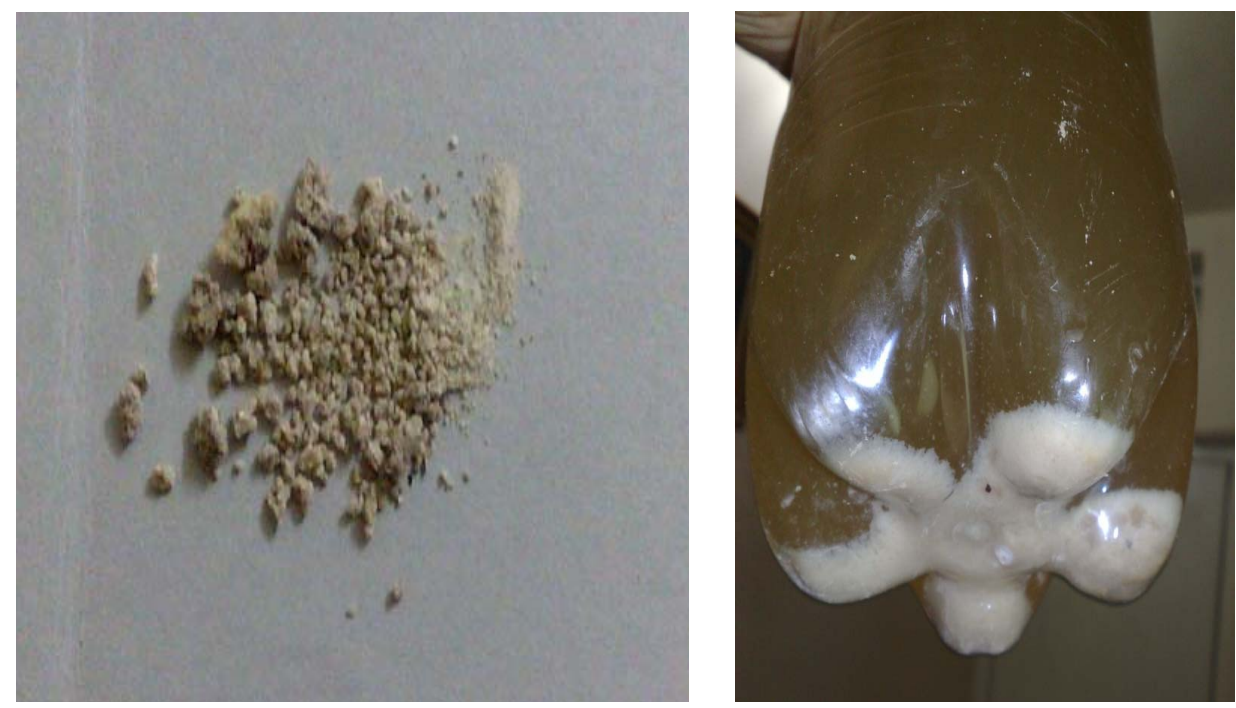

Figure 1. Types of gravels post ESWL $1^{\text {st }}$ picture reveals macroscopic gravels, $2^{\text {nd }}$ stone fragmented into sand like material. 


\section{Follow Up}

The patients were followed up with plain radiography and ultrasound to assess the stone-free status. Treatment was classified as stone free, presence of residual fragments $>5 \mathrm{~mm}(\mathrm{RF})$, and non-broken stone. Complications, ESWL re-treatments, and adjuvant procedures were documented.

\subsection{Statistic}

The statistical analysis in this study was performed using the Statistical Package for Social Sciences (SPSS), version 16 computer program.

In all tests, a $p$-value of $\geq 0.05$ was considered as statistically not significant, a value $<0.05$ was considered a statistically significant, and a level $<0.001$ was considered as statistically highly significant.

\subsection{Results}

A total of 332 patients 233 were males (70.1\%). patients with a mean (SD, range) age of 42.8 yr. Cases were categorized into stone free $n=251(75 \%)$, presence of residual fragment $n=45$ and $36(10.8 \%)$ cases stones were not broken.

The overall success rates for renal and ureteral stones were $n=251 / 48 \quad 75 \%$ and $77.4 \%$ respectively.

$45(13.5 \%)$ were have residual fragments. Failure to break the stones after three sessions was recorded in 36 cases $(10.8 \%)$.

Pelvic stone130 (39\%), calyceal stones 140 (42\%) and 62 ureteric stones. 266 (80.1\%) were opaque, while 66 $(19.9 \%)$ were lucent stone. Ureteric stent were used in $32(7.7 \%)$ patients. 150 stone were on right side, 169 on left side and 13 were bilateral. The rates of stone clearance were $81.4 \%$ and $73 \%$ for $10 \mathrm{~mm}$ or less and $10-20$ mm respectively.

Multiple ESWL treatment sessions were required in 232/332 cases (69\%). Complete stone fragmentation were achieved after one session in 86/332 (25.9\%) case, two sessions in 93 (28\%), three sessions in 47 (14.1\%), and more than three sessions in 25 (7.5\%). While $45(13.5 \%)$ ended with residual fragments.

Post-ESWL complications are listed in Table 1. Steinstrasse were recorded in 35 cases (10.5\%) and passed spontaneously in (71\%). 5 cases were treated with ESWL on leading fragment, two treated with meatotomy and 2 treated with ureteroscopy and stone extraction; one case ended with ureterolithotomy.

Five cases of $10 \mathrm{~mm}$ renal stone were migrated as a whole to upper ureter after one session of ESWL Figure 2. Three cases treated by ESWL on ureter and two cases managed by push bang and JJ stent insertion.

The stone-free rate was correlated with patient characteristics, stone features and type of lithotripter using the Chi-square test (Table 2). Of the 11 prognostic factors studied, 3 had a significant impact on success rate, namely the size of the stones, stone localization, and number of shock waves.

\section{Discussions}

Extracorporeal shock wave lithotripsy (ESWL) has been a major tool in the treatment of urinary stones for nearly three decades. In recent years, ESWL technology has been less effective at fragmenting stones than earlier devices [3] [5] [6].

The major draw-back of ESWL may be the need of repeated treatment sessions in a significant number of patients [3] [6].

The outcome of treatment after ESWL is variable due to the close relation between the final result with the stone burden, the existence of various types of lithotripters, different concepts of success and the way patients

Table 1. Post-ESWL complications.

\begin{tabular}{ccc}
\hline Complications & No. & (\%) \\
Pyelonephritis & 6 & 1.8 \\
Steinstrasse & 35 & 10.5 \\
Renal stone migrated to ureter & 5 & 1.5 \\
After ESWL & & \\
\hline
\end{tabular}


Table 2. Post-ESWL complications.

\begin{tabular}{|c|c|c|c|c|c|}
\hline & Parameter Stone Free & $\%$ & Residual Fragments & $\%$ & p Value \\
\hline Age (yr) & & & & & $>0.05$ \\
\hline$<40$ & 126 & 42.5 & 15 & 5 & \\
\hline$>40$ & 125 & 42 & 30 & 10 & \\
\hline Sex & & & & & 0.252 \\
\hline Males & 183 & 61.8 & 27 & 9 & \\
\hline Females & 68 & 22.9 & 18 & 6 & \\
\hline Stone Size Mm & & & & & 0.000 \\
\hline Up to 10 & 114 & 38.5 & 6 & 2 & \\
\hline $10-20$ & 124 & 41.8 & 31 & 10.4 & \\
\hline$>20 \mathrm{~mm}$ & 13 & 4.3 & 7 & 2.7 & \\
\hline Stone Side & & & & & 0.381 \\
\hline Right & 114 & 38.5 & 20 & 6.7 & \\
\hline Left & 126 & 42.5 & 23 & 7.7 & \\
\hline $\mathrm{Bi}$ & 11 & 3.7 & 2 & 0.6 & \\
\hline \multicolumn{6}{|l|}{ Localization } \\
\hline Pelvic & 103 & 34 & 19 & 6.4 & 0.005 \\
\hline Calyx & 100 & 33 & 25 & 8.4 & \\
\hline Ureter & 48 & 16 & 1 & 0.3 & \\
\hline \multicolumn{6}{|l|}{ Stone Radiology } \\
\hline Opaque & 199 & 67.2 & 36 & 12.1 & 0.82 \\
\hline Non Opaque & 52 & 17.5 & 9 & 3 & \\
\hline \multicolumn{6}{|l|}{ JJ stent } \\
\hline NO & 230 & 77.7 & 42 & 14 & 0.006 \\
\hline Yes & 21 & 7 & 3 & 2 & \\
\hline Renal Surgery for Stone & & & & & 0.406 \\
\hline No & 226 & 76 & 37 & 12 & \\
\hline Yes & 25 & 8 & 8 & 2.7 & \\
\hline No. of Shock Waves & & & & & 0.0 \\
\hline 3000 & 86 & 8 & & & \\
\hline $3000-6000$ & 93 & 13 & & & \\
\hline $6000-9000$ & 47 & 11 & & & \\
\hline$>9000$ & 13 & & & & \\
\hline Renal System State & & & & & 0.554 \\
\hline Perfect & 158 & 53.3 & 30 & 10 & \\
\hline Hydronephrotic & 93 & 31.4 & 15 & 5 & \\
\hline \multicolumn{6}{|l|}{ Lithotripter } \\
\hline Siemens & 153 & 51.6 & 31 & 10.4 & 0.3 \\
\hline Storz SLX F-2 & 98 & $33 \%$ & 14 & 4.7 & \\
\hline
\end{tabular}




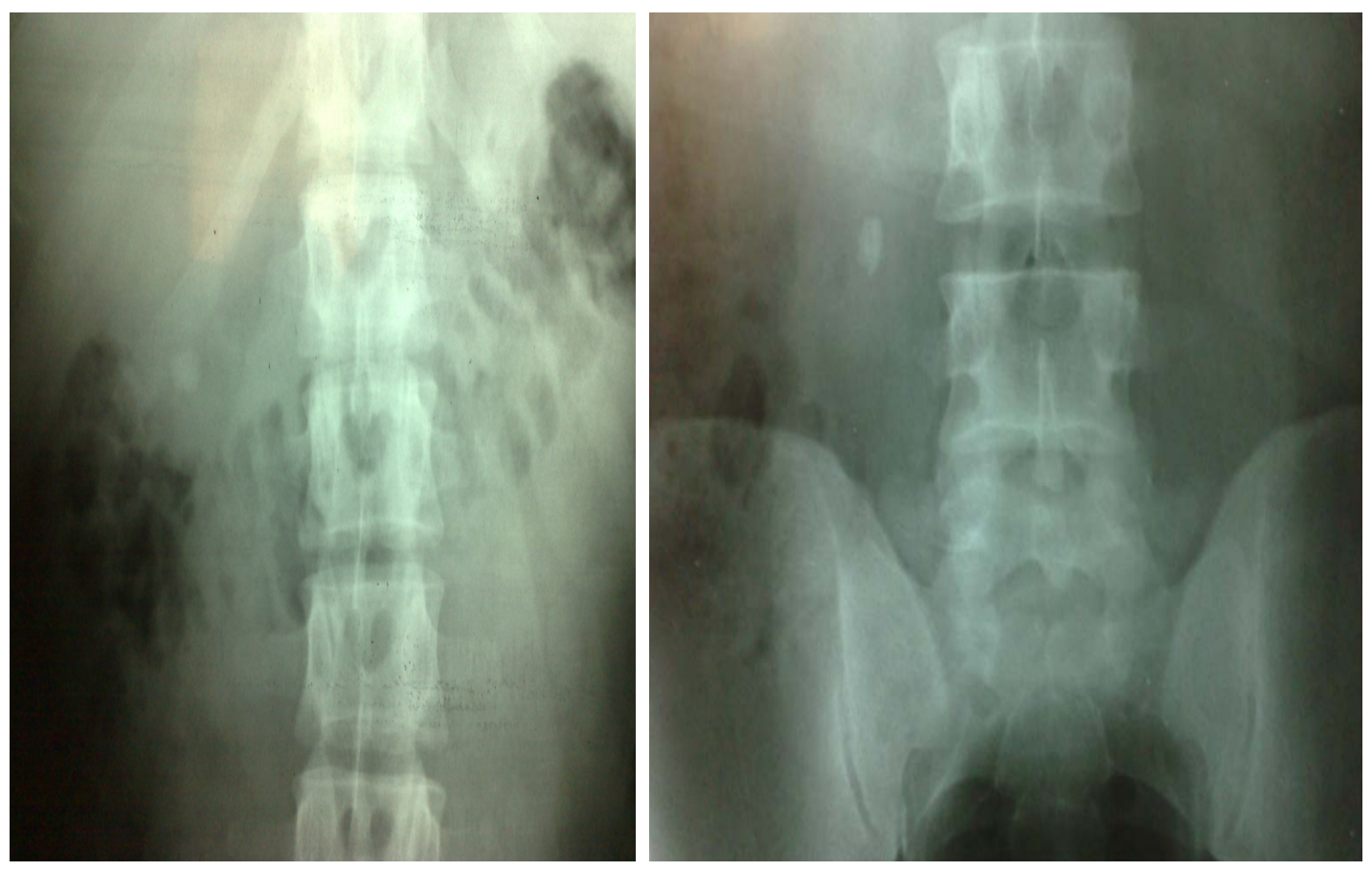

Figure 2. $1^{\text {st }}$ KUB film renal stone $2^{\text {nd }}$ film stone migrated to upper ureter after ESWL.

are evaluated after treatment. Because of these factors, stone-free rates following SWL vary from $14 \%$ to $91 \%$ [1] [5] [6].

We have observed that ESWL relieves renal pain in many patients, this might be a reason that we have large number 85 individual in whom received a session of ESWL and lost on follow up. How SWL relieve pain? Reasons are not fully understood, but might be the new blood vessels ("neovascularization") that are created by ESWL relieve pain [8].

Many factors are thought to influence the final results of SWL, including patient selection, stone size, stone location and composition, lithotripter type, experience level of the operator, total shock number, energy delivered, shock frequency and method of shock delivery [9]-[13].

In our study, the overall success of renal stone was $75 \%$ while $69 \%$ needed repeated sessions of ESWL. In our study, the stone free rate were $81 \%$ and $56.5 \%$ for stone less than $10 \mathrm{~mm}$ and larger than $20 \mathrm{~mm}$ respectively. Many investigators found that stone size play a key role in predicting the success of ESWL [1] [6] [11].

In general, as stone burden increases, the treatment success rate of ESWL will decline. When stone burden is less than $2 \mathrm{~cm}$, success rates are reported to be approximately $70 \%$ or greater [14].

Age and sex have no effect on ESWL success rate also in other studies these factors found play no effect [6].

We found pelvic stone has higher stone free rate $79 \%$ with $\mathrm{p}$ value 0.005 , this factor also found by many investigators that increase the probability of success of ESWL [6] [15].

In this study we found that the number of shock wave greatly influence the success of ESWL Multiple ESWL treatment sessions were required in 232 patients (69\%). 251 patients were stone completely fragmented. 86 (35.2\%) fragmented after one session, two sessions in 93 (37\%), three sessions in $47(18.7 \%)$, and more than three sessions in 25 (9.9\%). With p value 0.000 was highly significant.

In our study, $232(69 \%)$ required retreatment in comparison to other studies Assamy mention that (56.9\%) 338 required retreatment probably might due to Dornier MFL 5000 lithotripter machine that used [6].

We found no effect of previous renal surgery, ureteric stent and renal system state (hydronephrosis) on stone free rate.

Other study state that hydronephrotic kidney achieve lower success rate due to weak peristalses that lead to poor clearance of the fragments [6].

Many investigators believe that pre-ESWL JJ stenting of large renal stones helps to prevent Obstruction and facilitates passage of fragments [5]. On the other hand, many investigators showed that in situureteric stents im- 
pair ureteric peristalsis and/or trap large fragments, thus delaying stone clearance [15]-[19]. In our study, we found that pre-ESWL JJ stents did not significantly affect the incidence of neither complications nor stone clearance

In this study, the incidence of stenistrasse (SS) was $10.5 \%$ which is comparable to the other series. Steinstrasse is an uncommon event after ESWL and seems to occur more frequently with larger pelvic stones. All patients should be followed after ESWL, but SS should be specially suspected if there is macroscopic gravel elimination, flank pain and/or fever [16].

In this study, 5 patient with $10 \mathrm{~mm}$ pelvic stone were migrated to ureter after one session of SWL, that leads to repeated sessions of SWL, two cases need cystoscopy and using double J stent to push the stone back to renal pelvis.

We believe to avoid such misshapen need not to use high energy shock wave in small pelvic stone.

Its best to our knowledge that this misshapen not mention elsewhere.

The importance of factors such as stone size, stone site, and number of shock waves are important in predicting the ESWL success. In addition, modifications in shock wave delivery by altering shock rate and voltage have been researched in an effort to improve shock wave efficacy.

We didn't find statistical difference between the lithotripters Siemens and SLX F2, although the rate of stone free on Siemens was $76.5 \%$ while Storz SLX F2 was $74.2 \%$. As shown in Table 1, $p$ value 0.10 .

\section{Conclusions}

ESWL remains one of the most commonly utilized treatments for patients with upper urinary tract calculi; Stone diameter, location, and number of shock waves, are the most important predictors determining stone clearance after ESWL of renal and ureteric calculi.

To optimize treatment outcomes with ESWL, the presence of treating urologist is essential to optimize the final result.

\section{References}

[1] Matlaga, B.R. and Semins, M.J. (2009) How to Improve Results with Extracorporeal Shock Wave Lithotripsy. Therapeutic Advances in Urology, 1, 99-105. http://dx.doi.org/10.1177/1756287209104832

[2] Wiesenthal, J.D., Ghiculete, D., D’A Honey, R.J. and Pace, K.T. (2010) Evaluating the Importance of Mean Stone Density and Skin-to-Stone Distance in Predicting Successful Shock Wave Lithotripsy of Renal and Ureteric Calculi. Urological Research, 38, 307-313. http://dx.doi.org/10.1007/s00240-010-0295-0

[3] Tiselius, H.-G. (2008) The Low-Invasiveness of ESWL Combined with Its High Success Rate. When the EAU and AUA Expert Panel Had Reviewed the Recent Literature on the management of Patients with Stone.

[4] Elkoushy, M.A., Hassan, J.A., Morehouse, D.D., Anidjar, M. and Andonian, S. (2011) Factors Determining Stone-Free Rate in Shock Wave Lithotripsy Using Standard Focus of Storz Modulith SLX-F2 Lithotripter. Urology, 78, 759-763. http://dx.doi.org/10.1016/j.urology.2011.03.005

[5] Steinberg, P.L., Williams, S. and Hoenig, D.M. (2010) Adjuncts to Improve Outcomes of Shock Wave Lithotripsy Current Urology Reports. 11, 93-97.

[6] El-Assmy, A., El-Nahas, A.R. and Mohamed, E. (2006) Predictors of Success after Extracorporeal Shock Wave Lithotripsy (ESWL) for Renal Calculi between 20 - 30 mm: A Multivariate Analysis Model. The Scientific World Journal, 6, 2388-2390http://dx.doi.org/10.1100/tsw.2006.370

[7] Gallagher, H.J. and Tolley, D.A. (2000) AD: Still a Role for the Intravenous Urogram in Stone Management? Current Opinion in Urology, 10, 551-555. http://dx.doi.org/10.1097/00042307-200011000-00003

[8] Furia, J.P. (2005) Safety and Efficacy of Extracorporeal Shock Wave Therapy for Chronic Lateral Epicondylitis. The American Journal of Orthopedics, 34, 13-19.

[9] Yilmaz, E., Batislam, E., Basar, M., Tuglu, E., Mert, C. and Basar, H. (2005) Optimal Frequency in Extracorporeal Shock Wave Lithotripsy: Prospective Randomized Study. Urology, 66, 1160-1164. http://dx.doi.org/10.1016/j.urology.2005.06.111

[10] Albala, D.M., Assimos, D.G., Clayman, R.V., Denstedt, J.D., Grasso, M., Gutierrez-Aceves, J., et al. (2001) Lower Pole I: A Prospective Randomized Trial of Extracorporeal Shock Wave Lithotripsy and Percutaneous Nephrostolithotomy for Lower Pole Nephrolithiasis - Initial Results. Journal of Urology, 166, 2072-2080.

http://dx.doi.org/10.1016/S0022-5347(05)65508-5 
[11] Renner, C. and Rassweiler, J. (1999) Treatment of Renal Stones by Extracorporeal Shock Wave Lithotripsy. Nephron, 81, 71-81. http://dx.doi.org/10.1159/000046302

[12] Portis, A.J., Yan, Y., Pattaras, J.G., Andreoni, C., Moore, R. and Clayman, R.V. (2003) Matched Pair Analysis of Shock Wave Lithotripsy Effectiveness for Comparison of Lithotripters. Journal of Urology, 169, 58-62. http://dx.doi.org/10.1016/S0022-5347(05)64034-7

[13] Verze, P., Imbimbo, C., Cancelmo, G., Creta, M., Palmieri, A., Mangiapia, F., Buonopane, R. and Mirone, V. (2010) Extracorporeal Shockwave Lithotripsy vs. Ureteroscopy as First-Line Therapy for Patients with Single, Distal Ureteric Stones: A Prospective Randomized Study. BJU International, 106, 1748-1752.

[14] Galvin, D.J. and Pearle, M.S. (2006) The Contemporary Management of Renal and Ureteric Calculi. BJU International, 98, 1283-1288. http://dx.doi.org/10.1111/j.1464-410X.2006.06514.x

[15] Wiesenthal, J.D., Ghiculete, D., Ray, A.A., Honey, R.J. and Pace, K.T.A. (2011) Clinical Nomogram to Predict the Successful Shock Wave Lithotripsy of Renal and Ureteral Calculi. Journal of Urology, 186, 556-562. http://dx.doi.org/10.1016/j.juro.2011.03.109

[16] Lucio 2nd, J., Korkes, F., Lopes-Neto, A.C., et al. (2011) Steinstrasse Predictive Factors and Outcomes after Extracorporeal Shockwave Lithotripsy. Int Braz J Urol., 37, 477-482. http://dx.doi.org/10.1590/S1677-55382011000400006

[17] Argyropoulos, A.N. and Tolley, D.A. (2009) Ureteric Stents Compromise Stone Clearance after Shockwave Lithotripsy for Ureteric Stones: Results of a Matched-Pair Analysis. BJU International, 103, 76-80. http://dx.doi.org/10.1111/j.1464-410X.2008.07886.x

[18] Musa, A.A.K. (2008) Use of Double-J Stents Prior to Extracorporeal Shock Wavelithotripsy Is Not Beneficial: Results of a Prospective Randomized Study. International Urology and Nephrology, 40, 19-22. http://dx.doi.org/10.1007/s11255-006-9030-8

[19] El-Assmy, A., El-Nahas, A.R. and Sheir, K.Z. (2006) Is Pre-Shock Wave Lithotripsy Stenting Necessary for Ureteral Stones with Moderate or Severe Hydronephrosis? Journal of Urology, 176, 2059-2062. http://dx.doi.org/10.1016/j.juro.2006.07.022 